\section{Coupling tunable D-band directional coupler for millimeter-wave applications}

Weiye $\mathrm{Xu}$, Handong $\mathrm{Xu}$ and Fukun Liu

A coupling tunable D-band directional coupler is designed based on a novel coupling grid structure proposed in this letter. The designed directional coupler has excellent performance with ultra-wideband. The coupling can be tuned from $-28.2 \mathrm{~dB}$ to $-33.2 \mathrm{~dB}$ at $140 \mathrm{GHz}$ by changing the angle of the coupling grid, and the dynamic range of the coupling is about $5 \mathrm{~dB}$. The return loss is smaller than $-15 \mathrm{~dB}$ in the whole D-band from $110 \mathrm{GHz}$ to $170 \mathrm{GHz}$. A 3-dB coupler use the similar coupling structure is also designed. The coupling is $3.3144 \mathrm{~dB}$ at the center frequency of $140 \mathrm{GHz}$.

Introduction: Microwave directional coupler is a key microwave transmission device in many fields such as wireless communication, radar, and nuclear fusion plasma heating. Directional couplers can be implemented with a variety of transmission lines, such as coaxial line, rectangular waveguide, circular waveguide, stripline, microstrip line, and so on. Among them, the rectangular waveguide is the most widely used transmission line suitable for transmitting waves from several $\mathrm{GHz}$ to several hundreds of $\mathrm{GHz}$.

At present, the directional couplers suitable for waves from several $\mathrm{GHz}$ to several hundreds of $\mathrm{GHz}$ are mostly based on hole coupling [1, 2], waveguide T-Junction [3], etc. The bandwidth of the conventional design is usually small and the coupling is mostly fixed, which is inconvenient for ultra-wideband or large dynamic range applications.

In this letter, a novel ultra-wideband microwave directional coupler is proposed to remedy the defects of the conventional technology. The designed directional coupler has small return loss, good directivity, and the coupling can be tuned and the tuning range is large.

Directional coupler design: The designed D-band directional coupler is shown in Fig. 1. The coupler includes three parts: the WR-6 rectangular waveguides, the matching structures, and the coupling grid structure that consists of five metal strips. Where the matching structure is a miter bend, which is to ensure the wide side of the waveguide stays constant. The miter bends are only used between Port 1 and Port2, and between Port 3 and Port 4. The metal strips are made of copper-plated material. The five metal strips are distributed symmetrically and equidistantly. The distance between the centers of two adjacent metal strips is $\mathrm{s}=0.396 \mathrm{~mm}$. All metal strips have the same thickness, which is $0.02 \mathrm{~mm}$. If the five metal strips are numbered from left to right as No. 1 to No. 5. No. 1 and No. 5 have the same width, which is $\mathrm{d} 1=0.1328$ mm. No. 2, No. 3, and No. 4 also have the same width, which is $\mathrm{d} 2=0.0913 \mathrm{~mm}$. The coupling can be controlled by adjusting the angle of the coupling grid. The angle of the coupling grid shown in Fig. 1 is $90^{\circ}$ or $-90^{\circ}$. When the coupling grid rotates counterclockwise, the angle changes from $-90^{\circ}$ to $90^{\circ}$.

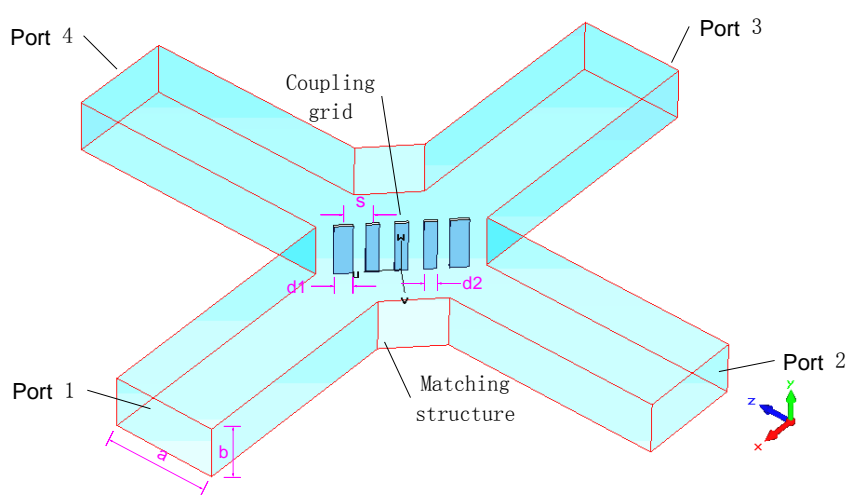

Fig. 1 Structure of the designed directional coupler. Where $a=1.651$ $\mathrm{mm}, b=0.8255 \mathrm{~mm}, s=0.396 \mathrm{~mm}, d 1=0.1328 \mathrm{~mm}, d 2=0.0913 \mathrm{~mm}$.

The simulation results of the designed directional coupler are shown in Fig. 2. The return loss is smaller than $-15 \mathrm{~dB}$ in the whole D-band from $110 \mathrm{GHz}$ to $170 \mathrm{GHz}$. The insertion loss $\mathrm{S} 21$ is greater than -0.55 $\mathrm{dB}$ in D-band and greater than $-0.15 \mathrm{~dB}$ at the center frequency of 140 $\mathrm{GHz}$. The coupling S31 changes from $-28.2 \mathrm{~dB}$ to $-33.2 \mathrm{~dB}$ at the center frequency with the angle of the coupling grid. The dynamic range of the coupling is about $5 \mathrm{~dB}$. The directivity S31-S41 is greater than $9 \mathrm{~dB}$ in $\mathrm{D}$-band and the directivity is greater than $16 \mathrm{~dB}$ at the center frequency of $140 \mathrm{GHz}$.
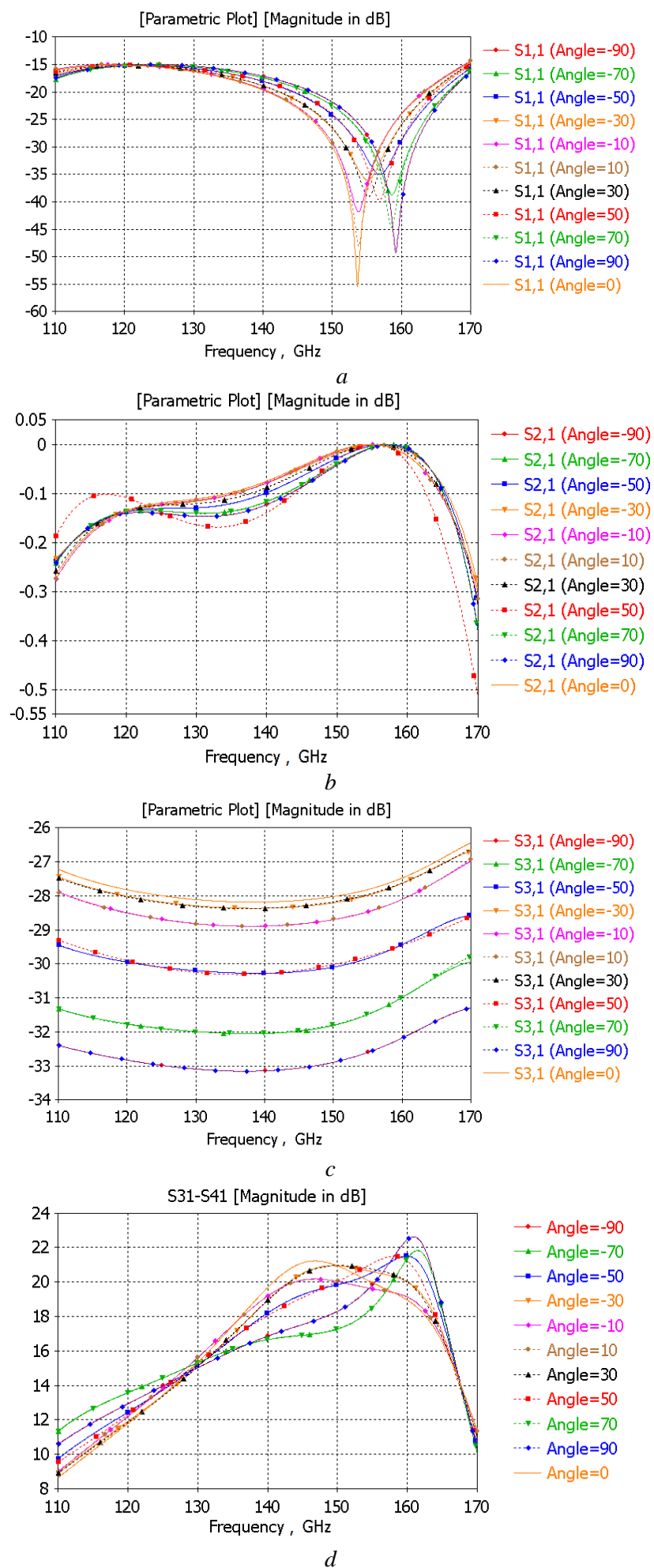

Fig. 2 Simulation results of the designed directional coupler.

a Return loss S11

$b$ Insertion loss $\mathrm{S} 21$

c Coupling S31

$d$ Directivity S31-S41.

Table 1 shows the performance comparison of the proposed work with previously reported coupler in the available literature. A novel coupling method is proposed in this letter. This design has wider bandwidth, and the coupling can be tuned by changing the angle of the coupling grid. This designed coupler is suitable for ultra-wideband and large dynamic range applications. 
Table 1: Performance comparison among proposed and reported couplers.

\begin{tabular}{|c|c|c|c|c|c|}
\hline Ref. & $\begin{array}{c}\text { Coupling } \\
\text { method }\end{array}$ & $\begin{array}{c}\text { Frequency } \\
(\mathrm{GHz})\end{array}$ & $\begin{array}{c}\text { Coupling } \\
(\mathrm{dB})\end{array}$ & $\begin{array}{c}\text { Directivity } \\
(\mathrm{dB})\end{array}$ & $\begin{array}{c}\text { Return } \\
\text { loss } \\
(\mathrm{dB})\end{array}$ \\
\hline $\begin{array}{c}\text { This } \\
\text { work }\end{array}$ & $\begin{array}{c}\text { Coupling } \\
\text { grid }\end{array}$ & $\begin{array}{c}110 \text { to } \\
170\end{array}$ & $\begin{array}{c}-28.2 \text { to }- \\
33.2 \mathrm{at} \\
140 \mathrm{GHz}\end{array}$ & $\begin{array}{c}\geq 9 \text { in } \mathrm{D} \\
\text { band, }>16 \\
\text { at } 140 \mathrm{GHz}\end{array}$ & $\begin{array}{c}\leq-15 \text { in } \\
\text { D band }\end{array}$ \\
\hline$[4]$ & $\begin{array}{c}\text { Hole } \\
\text { coupling }\end{array}$ & 22 to 26 & $\begin{array}{c}-20 \text { at } \\
24 \mathrm{GHz}\end{array}$ & $\begin{array}{c}\geq 9 \text { in } 2 \\
\mathrm{GHz} \text { range }\end{array}$ & $\begin{array}{c}\leq-15 \mathrm{in} \\
3 \mathrm{GHz} \\
\text { range }\end{array}$ \\
\hline$[5]$ & $\begin{array}{c}\text { Hole } \\
\text { coupling }\end{array}$ & 26 to 40 & $\begin{array}{c}-20 \text { at } \\
33 \mathrm{GHz}\end{array}$ & $\begin{array}{c}\geq 9 \text { in } 10 \\
\mathrm{GHz} \text { range }\end{array}$ & $\begin{array}{c}\leq-15 \mathrm{in} \\
14 \mathrm{GHz} \\
\text { range }\end{array}$ \\
\hline$[6]$ & $\mathrm{CRLH}$ & 24.5 to & $\begin{array}{c}-15 \text { at } \\
26.5 \mathrm{GHz}\end{array}$ & About 5 & $\geq-12 \mathrm{~dB}$ \\
\hline
\end{tabular}

The assembly of the directional coupler for D-band millimeter-wave applications is designed too, which is shown in Fig. 3. The flange adopts UG-387/U-M standard square flange. The flange and the metal shell are made of copper-plated material.

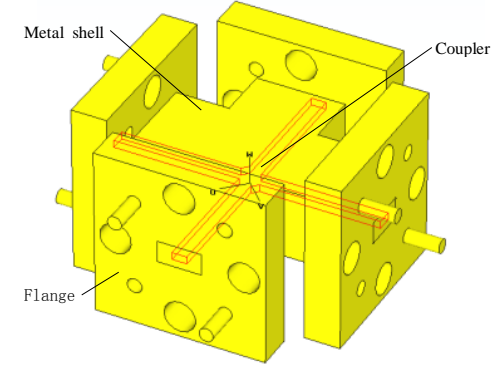

Fig. 3 Assembly of the designed directional coupler.

Actually, we can also design the directional couplers used in other bands from several $\mathrm{GHz}$ to several hundreds of $\mathrm{GHz}$ based on the coupling grid proposed in this letter. The only thing we should to do is to change the size of all structures.

As shown before, the coupling can be changed by changing the angle of the coupling grid. So we design a tuning mechanism shown in Fig. 4. A putter is fixed at the edge of the metal strips, and the angle of the coupling grid can be controlled by controlling the forward or backward movement of the putter. The putter is made of dielectric materials with high hardness, such as Poly Tetra Fluoro Ethylene (PTFE). The movement of the putter can be realized manually or by using a stepper motor. When the putter moves back or forth and drives the coupling grid to rotate, it will be caused to move left or right, too. Therefore, an elongated slit needs to be formed at the position where the putter extends out of the coupler metal shell. There are shafts at the center of the two ends of each piece of metal strip, which are inserted into the holes in the metal shell to realize the rotating support of the metal strip.

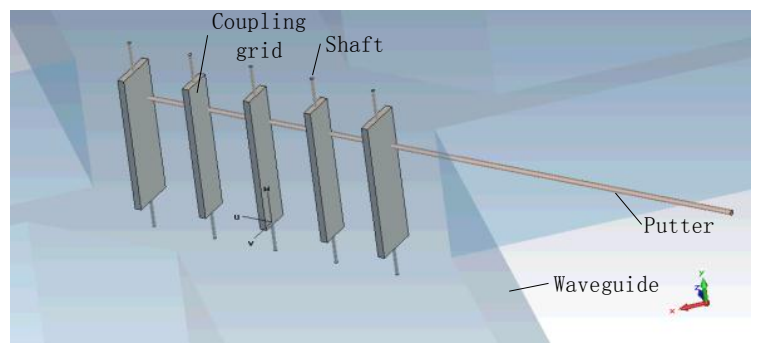

Fig. 4 Tuning structure of the designed directional coupler.

Discussion: In the preceding section, a coupler with the coupling from $28.2 \mathrm{~dB}$ to $-33.2 \mathrm{~dB}$ at $140 \mathrm{GHz}$ is designed. Actually, we can design a $3-\mathrm{dB}$ coupler use the similar coupling structure, which is shown in Fig. 5. The angle of the coupling grid is set to $-60^{\circ}$. All metal strips have the same thickness, which is $0.02 \mathrm{~mm}$.

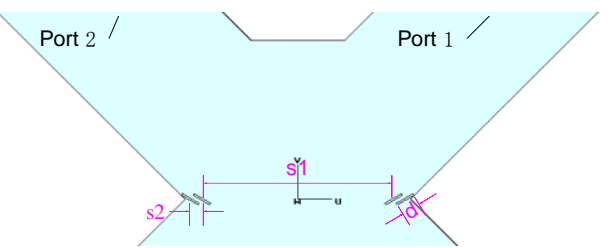

Fig. 5 Structure of the designed 3-dB directional coupler. Where $s 1=1.984 \mathrm{~mm}, s 2=0.12 \mathrm{~mm}, d=0.1 \mathrm{~mm}$.

The simulation results of the designed 3-dB coupler is shown in Fig. 6. At the center frequency of $140 \mathrm{GHz}, \mathrm{S} 21=\mathrm{S} 31=3.3144 \mathrm{~dB}$. Actually, the center frequency can be changed by changing the distance of $\mathrm{s}$. This design has wider bandwidth than that reported previously in the available literature [7, 8].

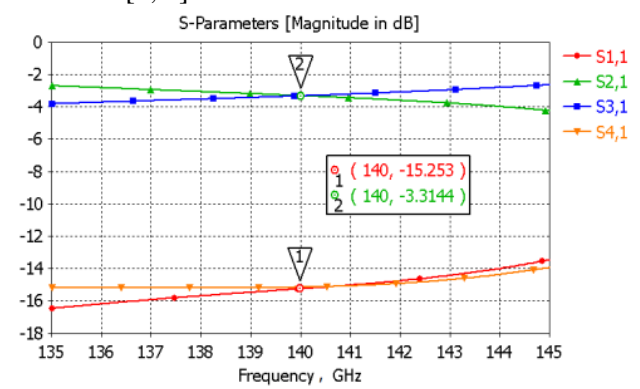

Fig. 6 Simulation results of the designed 3-dB directional coupler.

Conclusion: A coupling tunable D-band directional coupler is designed based on a novel coupling grid structure proposed in this letter. The designed directional coupler has excellent performance with wider bandwidth. It is suitable for ultra-wideband or large dynamic range applications. A 3-dB coupler use the similar coupling structure is also designed. The coupling is $3.3144 \mathrm{~dB}$ at the center frequency of 140 GHz. Actually, the directional couplers used in other bands from several $\mathrm{GHz}$ to several hundreds of $\mathrm{GHz}$ can also be designed using the coupling grid structure proposed in this letter.

Acknowledgments: This work was supported in part by the National Magnetic Confinement Fusion Science Program of China (Grant 2015GB103000 and Grant 2015GB102003).

Weiye Xu, Handong Xu and Fukun Liu (Institute of Plasma Physics, Chinese Academy of Sciences, Hefei, Anhui, 230031, China.)

E-mail: xuweiye@ipp.cas.cn

\section{References}

1. Bethe, H.A., 'Theory of Diffraction by Small Holes', Physical Review, 1944, 66, (7-8), pp. 163-182, doi: 10.1103/PhysRev.66.163

2. Cohn, S.B., 'Microwave Coupling by Large Apertures', Proceedings of the IRE, 1952, 40, (6), pp. 696-699, doi: 10.1109/JRPROC.1952.274063

3. Chi, W. and Zaki, K.A., 'Full-Wave Modeling of Generalized Double Ridge Waveguide T-Junctions', Ieee Transactions on Microwave Theory and Techniques, 1996, 44, (12), pp. 2536-2542, doi: 10.1109/22.554596

4. Guo, J. and Wu, K., 'Variable Propagation Constant Directional Coupler', Electronics Letters, 2017, 53, (6), pp. 419-421, doi: 10.1049/el.2017.0065

5. Parment, F., Ghiotto, A., Vuong, T.P., Duchamp, J.M., and Wu, K., 'Airto-Dielectric-Filled Two-Hole Substrate-Integrated Waveguide Directional Coupler', Ieee Microwave and Wireless Components Letters, 2017, 27, (7), pp. 621-623, doi: 10.1109/LMWC.2017.2711525

6. Sajin, G., Simion, S., Craciunoiu, F., Bunea, A.C., Muller, A.A., and Dinescu, A., 'Metamaterial Millimeter Wave Directional Coupler on Silicon Substrate', International Semiconductor Conference, Sinaia, Romania, December 2010, pp. 269-272, doi: 10.1109/SMICND.2010.5650770 7. Kong, W., Li, P., Chang, M., and Yang, G., 'Miniaturization Design of 3db Directional Coupler Applied to Balanced Power Amplifier in Wlan System', IEEE International Conference on Electronic Information and Communication Technology (ICEICT), Harbin, China, August 2016, pp. 571-573, doi: 10.1109/ICEICT.2016.7879770

8. Taeb, A., Basha, M., Gigoyan, S., Rafi, G., Chaudhuri, S., and SafaviNaeini, S., 'A Monolithic Low-Cost 3-dB Directional Coupler Based on Silicon Image Guide (Sig) Technology at Millimeter-Wave Band', IEEE MTT-S International Microwave Symposium (IMS), Honololu, HI, USA, October 2017, pp. 1102-1105, doi: 10.1109/MWSYM.2017.8058788 